\title{
Copyright for Online Teaching
}

Christine Fruin

Scholarly Communication and Digital Projects Manager, Atla

ABSTRACT When supporting instructors in the development of online course materials, librarians frequently encounter questions regarding fair use and other copyright and licensing issues surrounding the delivery of course content in an online classroom or through course management systems that support traditional face-to-face teaching. The fair use statute is the primary law by which use of course materials online is evaluated. However, considerations of contract or license agreements must also be made when using digital or streaming materials. Special considerations exist as well depending on the material type.

\section{BEFORE USING MATERIALS ONLINE}

Whether you seek to show a film clip, distribute a journal article, or otherwise use a copyrighted work in an online course, there are three questions you should ask:

First, is the material you are using still in copyright? That is, is it in the public domain or otherwise not subject to copyright protection? Only if a work is still subject to copyright protection must an exception under the Copyright Act or permission be explored.

Second, is the material you are using subject to a license agreement or other contract that may alter rights under the Copyright Act? A contract or license for access to electronic materials, such as e-journals, and terms of use accompanying purchases of media, such as DVDs and digital music, may affect a user's rights under the Copyright Act. Before using or reproducing such materials, you will want to review any applicable license or use agreement. In many instances, a stable link to a licensed resource should be used instead of transmitting the work by posting a copy of it into a course management site, electronic course reserves or some other system. 
Third, does the proposed use of a copyrighted work qualify as a fair use? If the balancing of the four factors of fair use does not weigh in favor of use, you will need to seek permission from the copyright owner.

\section{WHAT IS COPYRIGHTED?}

Copyright law protects only those works that are original and that are fixed in a tangible medium of expression. These include not only literary works but also musical compositions and performances, sculptures and other works of art, architectural drawings, and even software. To be entitled to copyright protection, a work does not have to be formally published. Even unpublished works are subject to copyright protection. Further, works found freely online, such as text and images on web pages, may also be protected by copyright.

A creator's monopoly on the use of their copyrighted works includes a bundle of exclusive rights, including the right to copy their own works, the right to perform or display those works publicly, the right to distribute those works to the public (whether for free or for profit), and the right to prepare derivatives of those works. Since 1989 , no formal steps are required to be completed by a creator in order to be entitled to copyright protection. There is no requirement of notice or registration unless and until one seeks damages in a copyright infringement lawsuit.

The duration of copyright protection is limited, although a very lengthy time of protection is now granted. For works created in the U.S. after 1978, copyright lasts for the life of the author plus seventy years. Copyright protection for most works created in the U.S. before 1924 has expired, and those works are thus considered to be in the public domain. For works created in the U.S. between 1923 and 1978 , calculation of the term of copyright depends upon a variety of factors, including whether formalities no longer required such as registration and renewal of copyright were complied with.

Although the law grants creators and authors certain exclusive rights with respect to how they may re-use their works, there are limitations expressed in the Copyright Act that permit educators to re-use a copyrighted work without first seeking the creator's permission. 
Section 110(1) of the Copyright Act allows educators to perform or display, without the copyright holder's permission, copyrighted works in a face-to-face teaching environment. This exception only applies to works that are capable of being performed or displayed, such as films and songs-it does not apply to the reproduction or distribution of other types of copyrighted works. Further, it only applies to performances and displays that are relevant to the teaching goals of the course-showing a film as a reward is not covered by this exception, and in those cases it would be a public performance necessitating a license or permission.

The exception of 110(1) was expanded in 2002 by the enactment of the TEACH Act. The TEACH Act, enacted primarily in section 110(2) of the Copyright Act, permits the digital performance or display of copyrighted works in a distance classroom but only under very limited circumstances as compared to the face-to-face teaching exception. The TEACH Act only applies to copyrighted works capable of being performed or displayed, such as movies or sound recordings. It does not apply to digital delivery of print works, such as electronic course reserves or posting of materials in a course management system. The TEACH Act imposes several requirements upon the educational institution and upon the instructor before it may be invoked. Because of the complexities and the complications in understanding the TEACH Act and its application, copyright experts are generally in agreement that it should not be utilized.

A third exception that applies to teaching activities and that is the preferred method for making materials available online is fair use. Under fair use, one may reuse or reproduce a copyrighted work without permission where the purpose of the use is criticism, comment, news reporting, scholarly, research, or education, and where the balance of four separate factors weighs in favor of such use.

\section{FOUR FACTORS OF FAIR USE}

The four factors of fair use can be best summarized as follows: what is the purpose and character of the use; what is the nature of the copyrighted work; how much of the work is used and does this portion represent the "heart of the work"; and finally, what effect does the use of the copyrighted work have on the market and value 
of the work.

Consideration of all the fair use factors is required; however, all four factors do not have to weigh equally in favor of the proposed use. A fair use analysis is fact-driven; it is intended to be utilized in a case-by-case fashion. Each unique set of facts regarding a proposed use leads to its own reasoned conclusion. Reasonable individuals may come to different conclusions concerning the same set of facts, but the operative word is "reasonable."

When analyzing each factor, there are several inquiries that you can make to assist you in reaching a determination.

When examining the purpose and character of the use, consider whether the use is for educational or commercial purposes. In the cases of commercial uses, courts have indicated that if the use is significantly transformative, that is, the use of the work is a completely new, unexpected, or unintended way, and not merely a reproduction and distribution, this factor may weigh in favor of a finding of fair use. The argument of transformativeness may also apply, however, to the non-profit, educational context. For example, is a series of scenes from a Hollywood blockbuster selected to depict how an individual struggles with his sense of morality, or has the film been chosen for the entertainment value of the special effects? If a work is reproduced in significant quantities but for a purpose not originally intended by its author, then that reproduction and use may be considered transformative for the purpose of fair use analysis.

When considering the nature of the work, analyze whether the content is technical or fact-based, or is it more artistic and creative? Remember, facts or common technical knowledge are not subject to copyright protection.

Looking at the quantity of a copyrighted work used, a smaller amount ordinarily will weigh more in favor of fair use than using the whole work. However, be mindful of whether your selection of text or content would represent the "heart of the work" because, if so, this may weigh against a finding of fair use.

Finally, in conducting a fair use analysis, one must consider the effect of the use upon the market for the copyrighted work. This factor has garnered increased attention in recent cases interpreting the Copyright Act, with courts looking at whether the use or repro- 
duction is solely for the purpose of cost savings, whether it be for students or for the institution. The market effect inquiry should also look at whether there is a ready market for the original work, including a readily available licensing scheme, that would be impeded by the proposed use.

\section{COPYRIGHT AND CONTRACTS}

Electronic or digital materials, whether accessed through your institution's subscription or from an instructor's personal copies, are often subject to a license or "Terms of Use." These licenses are contracts that are entered into between the provider or producer of the content and the purchaser or subscriber. Most licenses speak to permitted and prohibited uses and frequently reference fair use or other copyright provisions. It is important to be familiar with the language of the license agreement, particularly whether a particular use of electronic or digital material is prohibited in the context of posting or sharing through a course management system or other online learning platform. Even if the proposed use would be permitted by fair use, the terms of the license agreement ultimately control.

\section{USING TEXT MATERIALS ONLINE}

Several questions may arise when considering the use of text materials in an online course. When selecting text materials, determine whether the institution owns a digital or electronic version of the book or article the instructor wishes to use in the course. If so, he or she may be able to simply provide students with a stable or persistent link to the work rather than copying the work into the online course; in many cases, this is all that is permitted by the license agreement. Because most electronic resources are subject to a license agreement, the terms of the license, a contract, take precedence over what the Copyright Act and fair use would otherwise allow.

If you cannot link to an existing electronic source and you need to scan a copy of an article or book chapter, you should apply fair use. When conducting a fair use analysis for posting text materials, pay particular attention to the quantity of the work you have selected-is the amount selected essential to the pedagogical goals of the class? Other important considerations when evaluating fair 
use are the availability of licensing or permissions for the work and the commercial availability of the work for student purchase.

Finally, when looking for text materials to use in an online class, consider using works published through an open access press or in an open access journal. Open access works are quality, peerreviewed scholarly works that are still copyrighted but are freely available to anyone online, typically through an open license. For a list of open access journals, visit the Directory of Open Access Journals (http://www.doaj.org). If the selected text is a journal article, it is possible that the author has posted a pre-print version of the manuscript in his or her own institutional repository or even a subject-based repository. Those versions may be accessed without a subscription and may generally be freely linked to for student access.

\section{USING VIDEO ONLINE}

In addition to consideration of the factors of fair use when evaluating use of video online, there are several other considerations that need to be made. When creating video clips from DVDs for streaming, educators need not worry about violating the terms of the Digital Millennium Copyright Act, also referred to as the DMCA, which generally prohibits circumventing the technological protection measures embedded in digital media to prevent copyright or "ripping." Faculty from any discipline are permitted under rules promulgated by the Library of Congress and Register of Copyrights to create digital clips of DVD films.

Even if streaming of a film would be allowable under fair use or the DMCA, by purchasing a DVD, the purchaser is agreeing to whatever terms of use or license accompany the DVD, and those terms must be complied with. Many film distribution companies offer licenses to digitize and stream their works, whether by digitizing and streaming the physical copy owned by the institution or by accessing an IP-authenticated portal set up for the institution by the film's distributor or other copyright holder. Additionally, many educational publishers produce and market video content specifically for education and provide parameters in a license agreement or other terms of use as to how that content may be used, or alternatively, some film 
production and distribution companies now include terms of use or licenses with their DVDs. Oftentimes there is language contained therein specifically prohibiting the streaming of any quantity of the film to an online course.

Instructors may also want to consider one of the low-cost or free options for streamed video content. With a basic Netflix account, which most students likely have, thousands of films, including foreign and documentary works, can be accessed by the subscribing student. Note, however, the terms of the Netflix user agreement would not permit the sharing of your own Netflix user account details with students or showing a streamed film in a physical classroom. Amazon and iTunes also offer inexpensive rental of streamed video content. There are also many websites providing legal and no-cost quality streamed video content. For example, PBS offers many of its programs, including Independent Lens, Frontline, and Nature, for free viewing online. Other great sites for legal streaming documentary film content include SnagFilms.com and TopDocumentaryFilms.com.

A word of caution about video content found on services like YouTube or similar sites: some content posted on YouTube is in violation of copyright law and, upon receipt of a complaint of infringement, it will be removed. When providing students with a link to material found on YouTube or similar video hosting services, bear in mind that if the content has not been posted by the copyright holder or with the copyright holder's permission, it may not be available for the duration of the course if there is an intervening takedown notice. Further, it is a best practice to provide only a link to this content rather than utilizing any video capturing software and thereby making a copy of a potentially illegal copy and streaming it from a local server. For more information on showing movies in class please see the Atla LibGuide on Showing Movies in Class and on Campus (https://atla.libguides.com/copyright/showingmovies).

\section{USING SOUND RECORDINGS ONLINE}

Sound recordings can come from a variety of sources: CDs, digital formats like MP3, phonographs, and cassettes. Analyze usage of sound recordings for fair use, and if fair use does not apply, you 
must seek permission of the copyright holder prior to transmitting audio works to an online class.

Analog musical works may be digitized for purposes of online education if a digital component is unavailable. It is also important to remember that digital recordings of music, such as music obtained from iTunes, often have license restrictions on how it may be used. Again, a license is a form of contract, and the terms of that contract would control, regardless of what is permitted under exceptions in the Copyright Act.

There are many resources that online educators can refer to for finding free, streaming audio works. Many contemporary composers license their works using Creative Commons licensing. Creative Commons works can be found on several sites such as Jamendo (http://www.jamendo.com). The Library of Congress also hosts the National Jukebox, which is a large repository of recordings, musical and speech, made between 1901 and 1925.

\section{USING IMAGES ONLINE}

An important consideration when using images in your online course is ensuring that the source of the copy is legal. This issue arises frequently when copying images from an online source. Online educators must use caution when culling images from the Internet and using them in their courses. Before using such content, take steps to ascertain whether the original image is being used in an infringing manner. Knowingly using illegal content, even under a claim of fair use, does not eradicate the initial infringement.

Another question that frequently arises with the use of images concerns how many images by any single artist may be used and, relatedly, whether the new use is transformative enough to counter any challenges to the quantity used. The imposition of a quantity limit often arises when using copyrighted images. However, court decisions from the past twenty years instruct us that the number of images is not as important as how those images are being used. The question to ask is how transformative is the new use of the images not only in purpose but also in quality and size? When applying a fair use analysis to your use of images in an online course, these will be important considerations to be weighed and balanced. 
As an alternative to using strictly copyrighted images, consider using images in the public domain or licensed using a Creative Commons license. There are many quality repositories available online containing public domain or Creative Commons-licensed images. The Creative Commons organization provides a search engine on its own website that retrieves images from several popular image-hosting domains according to the term and license parameters you specify. There are also several government and privately sponsored sites of public domain images, including photographs, maps, and other drawings. 